\title{
Migration and sexual behaviour among youth in Nairobi's slum areas
}

\author{
Kanyiva Muindia ${ }^{1 a}$ Netsayi Mudege ${ }^{b}$, Donatien Beguy ${ }^{a}$ and Blessing U Mberu ${ }^{a}$ \\ ${ }^{a}$ African Population and Health Research Center, Nairobi, Kenya.

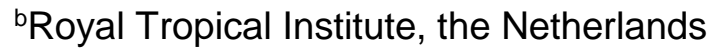

\begin{abstract}
Migration remains an important event in the urbanization process. However, research evidence indicates that migration is associated with negative outcomes. For migrant youth, migration often coincides with leaving home and divesting of parental authority and controls. This study investigates migration as a determinant of risky sexual behaviours and the factors influencing the timing of first sex among migrant youth. We used data collected between 2006 and 2008 from youth aged 12-22 years living in two slums in Nairobi. We use Cox proportional hazards model for timing of first sex among migrants and logistic regression for determinants of risky sexual behaviour. Migration is important for number of sexual partners but not for sexual debut. The risk of initiating first sex soon after in-migration is higher for youth with problem behaviour. Among adolescents in Nairobi's slums, migration is not associated with a higher risk of engaging in risky sexual behaviour. However, youth with problem behaviour face a higher risk of initiating sex soon after migration.
\end{abstract}

Keywords: Migration; youth; sexual behaviour; slums; Nairobi

\section{Résumé}

La migration demeure un évènement important dans le processus d'urbanisation. Toutefois, de plus en plus preuve de recherche indique que la migration est associée à des effets négatifs chez les migrants. Pour les jeunes migrants, la migration coïncide souvent avec le départ du foyer et la cession de l'autorité parentale et des contrôles. Cette étude examine la migration comme un déterminant des comportements sexuels à risque et les facteurs qui influencent le choix du moment de premier sexe parmi le jeune migrant. Nous utilisons les données recueillis entre 2006 et 2008 des jeunes âgés entre 12 et 22 ans vivant dans deux bidonvilles de Nairobi. Nous utilisons le modèle de hasards proportionnels de Cox pour le chronométrage des premiers rapports sexuels chez les migrants et l'analyse de régression logistique pour les déterminants des comportements sexuels à risque.

L'état de migration est important pour le nombre des partenaires sexuels mais pas pour le début sexuel. Le risque de lancer premier sexe peu après la migration augment avec l'âge lors de la migration et pour les jeunes avec problèmes de comportement. Parmi les adolescents dans les bidonvilles de Nairobi, la migration n'est pas associée à un risque plus élevé de l'engagement de comportements sexuels à risque. Pourtant, les jeunes ayant des problèmes de comportement face à un risque plus élevé d'initier le sexe dès après la migration.

Mots clés: migration; la jeune; comportement sexuel; bidonvilles; Nairobi

\footnotetext{
${ }^{1}$ Corresponding author. Email: kmuindi@aphrc.org or kanyiva@gmail.com

P.O. Box 10787-00 I00 Nairobi. Telephone +254-20-400 I000. Fax: +254-20-400 I I0 I
} 


\section{Introduction}

The increase in internal migration and the rate of urban growth associated with economic and political transitions in Africa, Asia, Latin America and the Pacific (Gurmu et al., 2000) have placed migration at the centre of development policies and programs in these regions. Scholars increasingly acknowledge urbanization as an intrinsic dimension of economic and social development, reflecting the rational decisions of millions of internal migrants to seek new opportunities in cities (White et al., 2008). However, there is considerable concern in subSaharan Africa regarding the implications of urbanization for development, poverty, health, environmental quality and social welfare provision. This concern derives from increasing evidence that urbanization without industrialisation in the region has been a source of growing poverty, rather than of economic dynamism. The consensus is that rapid urbanization without economic growth in subSaharan Africa has created a new face of poverty characterized by a significant proportion of the population living below the poverty line in overcrowded slums and sprawling shanty towns around major cities, with attendant high levels of unemployment and underemployment, crime, general debilitating environmental conditions, risky reproductive behaviour and poor health outcomes (UN-HABITAT, 2003, National Research Council and Institute of Medicine, 2005, African Population and Health Research Center, 2002, Mabogunje, 2007).

\section{Literature Review}

African migration is mostly labour-motivated, with particularly young people moving into cities in search of economic opportunities (Townsend, 1997, NISER, 1997, Mberu, 2005). The downside however, is the growing evidence linking the high rate of youth migration to urban and economic centres in search of livelihood opportunities, in the context of persistent poverty, to increased sexual risk taking among young people (Isiugo-Abanihe and Oyediran, 2004, Adedimeji, 2005, Blanc and Way, 1998). The prognosis of this linkage is not particularly optimistic, following suggestions that the massive migration of young and unmarried adults from presumably conservative rural environments to more sexually permissive African cities in recent years, has been partly responsible for the much higher HIV sero-prevalence levels observed in urban than rural areas (Brockerhoff and Biddlecom, 1999,
United-Nations, 1994, Quinn, 1994). Other studies have found that migrants, particularly men who live away from their wives are involved in risky sexual practices that elevate their risk of acquiring HIV/AIDS (Lurie et al., 2003). Beside HIV/AIDS and other sexually transmitted infections (STIs), early pregnancy and pregnancy complications, unsafe abortion and early child bearing (Gage, 1998, Blum, 2002), are outcomes that are collectively antithetical to young people's successful transition to adulthood.

Kenya typifies the challenges of increased rural urban migration leading to urban population boom, 'slumization' and associated urban health and poverty problems. Between 1980 and 2000, its urban population increased at an annual rate of $7.2 \%$, whilst per capita GDP dropped annually by about 0.1\% (Central Bureau of Statistics, 2000). The number of Kenyans living in urban areas has increased by $26 \%$ from 9.9 million in 1999 to 12.5 million in 2009, amounting to about $32 \%$ of the total population in 2009. While statistics differ, over a third of Kenya's urban population is living in poverty by any measure and recent figures indicated levels closer to a half. Estimates suggest that by 2020 , urban poverty will represent almost half $(48.9 \%)$ of the total poverty in the country (Kessides, 2006).

Nairobi, the capital city has long grown into a poverty hub with about $60 \%$ of its population, around 2 million people, living in slum settlements or slum-like conditions, occupying only $5 \%$ of the residential land area of the city (Matrix Development Consultants, 1993, UN-HABITAT, 2003). There are over 4 million urban food-poor in Kenya, almost a third of whom are located in Nairobi, and while inequality is declining in Kenya's rural areas, it is high and rising in the cities. The rural Gini coefficient is now around a low 0.38 similar to Portugal and much lower than that of the United States, but in Nairobi, it is a staggering 0.59 , indicating very high levels of inequality similar to Johannesburg in the mid-1990s (Oxfam, 2009).

Building on Kenya's migration, urban population and poverty profiles, this paper investigates the relationship between migration and sexual risk behaviour among adolescents aged between 12-22 living in two informal settlements of Korogocho and Viwandani, in Nairobi city. The study seeks to contribute to on-going research efforts on the linkages between migration and sexual behaviour in sub-Saharan Africa, by focusing specifically on young migrants living in the rapidly growing urban slum settlements in the region, that have rarely been studied. Building on empirical evidence that 
adolescent sexual activity, such as premarital sex, is part of other deviant trajectories (French and Dishion, 2003) and guided by findings that the slum environment in Nairobi breeds a group of other adolescent problem behaviours (Mugisha et al., 2003), we focus on two related sexual behaviour outcomes: timing of sexual debut, and multiple sexual partnerships over the last year.

Our overarching question is whether migrant adolescents living in poor urban settings, such as slum settlements, are more vulnerable to early initiation of unprotected sex. Against the backdrop of empirical and theoretical literature, we hypothesize that migrant youth in the slums of Nairobi are more likely to engage in sexually risky behaviour compared to non-migrants. Previous research have underscored the unique challenges posed by a hostile environment characterized by high levels of unemployment; crime, substance abuse; poor schooling facilities; and lack of recreational facilities, for young people in both informal settlements as they transition to adolescence and adulthood (African Population and Health Research Center, 2002, Taffa, 2003, Mugisha et al., 2003, Mugisha and Zulu, 2004). Other evidence point to adolescents in the slums of Nairobi initiating sex about 3 years earlier and they are 2 times more likely to have multiple sexual partners than adolescents who live in non-slum parts of the city (Zulu et al., 2002). Also while abject poverty in the slum settings has been found to drive indulgence in risky sexual behaviour, the particular role of migration is yet to be determined. This becomes even more important following findings that youth migration may often coincide with leaving home and divesting of parental authority and controls (Smith, 2000), together with a lack of alternative social network in the city. Moreover, youth migration might result in change in "outlook on sexual norms and behaviours in the quest to fit into a new social context". Untangling these scenarios to determine the independent role of migration on risky sexual behaviour will be an important contribution to the literature and an evidence base for the design of youth targeted behaviour change policies.

\section{Context}

Korogocho and Viwandani are located about 7-12 $\mathrm{km}$ from Nairobi city centre and about $6 \mathrm{~km}$ from each other. Most of the residents of Korogocho are either uneducated or dropped out of school at primary level; only $19 \%$ of men and $12 \%$ of women attained a secondary education (Zulu et al., 2006). On the other hand, Viwandani which covers an area of about 3 kilometres length, and I kilometre width is close to Nairobi's industrial area where many of its residents earn a living by working in the factories. The two study communities also present some differences with regards to population stability. Korogocho is more settled as opposed to the youthful and highly mobile population in Viwandani. Results from an earlier study show that Korogocho residents have lived in the community for an average of 16 years while in Viwandani the average duration of stay is about 8 years (Zulu et al., 2009). The average duration of stay for this sample is discussed later in the paper.

\section{Data and Methods}

\section{Source of data}

This paper draws on data from two projects under the Urbanization, Poverty and Health Dynamics program (UPHD) nested onto the on-going Nairobi Urban Health and Demographic Surveillance System (NUHDSS) set up in 2000 by the APHRC to collect routine demographic and health data from residents in the two informal settlements. The surveillance occurs in a clearly defined area, the Demographic Surveillance Area (DSA). As at the end of 2009, the NUHDSS covered nearly 76,000 people living in 29,900 households (African Population and Health Research Center, 2009). The first data set is from the UPHD transitions to adulthood study component conducted in 2007. Data were collected from 4,058 youth aged between 12 to 22 years residing in Korogocho and Viwandani at the time of sampling. The study aimed at identifying the risk as well as protective factors among youth as they experience the different events leading to adulthood. Available data in the transitions study covers reproductive aspirations (e.g. regarding parenthood, marriage) and key health and other concerns (e.g. worry about HIV/AIDS, getting a job, marriage, finishing school, employment); nature of interactions with parents, guardians, teachers, and peers; involvement in youth groups (including religious ones); and indulgence in risky behaviours (sexual debut, multiple sexual partnerships, non-use of condoms, smoking, use of illicit drugs and alcohol consumption). These events were updated once a year for three years since 2007 to assess factors affecting timing and sequencing of the transitions, and their impact on later life chances. 
The second dataset used in this paper comes from the UPHD migration component. Data were collected from a random sample of residents in the aforementioned slums between October 2006 and April 2007. Ten year migration histories were collected for 16,400 individuals aged 12 years and above. In addition, data were collected on income generation at the time of the survey. Close to 4,000 of this target sample were aged between 12 and 22 years. The study collected detailed migration histories, to understand where the respondents had lived prior to coming into the slums, and also investigated reasons for migration among residents in Nairobi's informal settlements. Other information collected included data on socioeconomic status prior to the last migration and socioeconomic linkages with origin homes.

The third dataset is the routine household poverty data collected once every year from all NUHDSS households residing within the study areas. We use data collected in 2007 and 2008 to enable each household represented in the sample to have information on the poverty status as close as possible to the data collection dates of the other two studies mentioned above. Information collected includes source of drinking water, access to toilets, as well as ownership of household durable goods. Poverty indices used in this paper were computed as composite indices incorporating assets ownership and other dimensions of poverty such as dwelling comfort and income.

After merging the three datasets, we end up with 3,200 individuals in the analytical sample who have records from the three datasets Weights were computed for the analytical sample to make its distribution comparable to that of the initial sample, with respect to characteristics such as age, gender, slum of residence, level of education and ethnic group of individual.

\section{Measures}

\section{a) Outcome variables}

Indicators of risky sexual behaviour are measured through two outcome variables namely: age at sexual debut and number of sexual partners in the year preceding the interview.

Sexual debut is a measure looking at the age at which respondents initiate sex. Early sexual debut was defined as initiation of sexual activity at the age of 14 years and below while late debut was defined as first sexual intercourse at 15 years and above. This outcome was derived from the question "how old were you when you had sex for the first time?" It includes both the married and unmarried respondents. The cut-off at 14 years was picked based on studies that have documented that youth in slums initiate sex earlier than those residing in non-slum urban areas and in rural areas (Zulu et al., 2002). In addition, the sample's median age at first sexual encounter is 15 years.

The number of sexual partners in the year preceding the interview was derived from the question "in the past year, how many people, if any, have you had sexual intercourse with?" This outcome was considered for both those within a marital union and those not in any union at the time of the interview.

Lastly, for timing of first sex among migrant youth, the outcome variable is based on responses to the following three questions: "... Have you ever had sex?" and if so, "In what month and year did you have your first have sexual intercourse", "How old were you when you first had sexual intercourse?" The outcome variable is the age at which a person makes the transition to first sex (uncensored individuals) or age at interview if the event had not occurred as at the time of the survey (censored individuals). A dichotomous variable (coded $I$ if first sex had occurred and 0 if not) is used to define the censoring status.

\section{b) Independent variables}

This paper is focusing on timing of first sex for migrants as well as subsequent risky sexual behaviour for all respondents while controlling for their migration status which is the main independent variable. The migration status of each individual is derived from the migration history data where a question was asked to each about the length of stay in the study sites. For those who were born in the DSA and had never left for a period of three or more months, the response was "since birth". For those born in the DSA and left for at least three months, the question "in what month and year did you first come to Nairobi?" allows us to define them as DSA born since their response would be "not applicable". Further to this measure of lifetime migration status, we control for another measure of migration that takes into consideration the age at which the migrant moved into the slums. This is a categorical variable that considers a migrant to be 'slum socialized' if he/she moved into the slums when aged 12 years or below. Individuals who moved into the slums after the age of 12 years are considered as 'non-slum socialized migrants'. The 
last category is the slum-born which constitute individuals who were born and have always lived in the slums.

Our review of relevant literature have identified important predictors of risky sexual behaviours, informing the control for variables such as father's and mother's presence in their lives, marital status, involvement in income-generating activities, education level, ethnic group, gender, age, religious affiliation and age at migration, duration of stay in slum area and household socio-economic status captured through a wealth index based on household possessions and amenities. Other independent variables included are religiosity, problem behaviour and parental monitoring. Religiosity score was based on ten items that capture the importance of religion in youth's lives as well as observance of religious laws and teachings. Perceived parental monitoring was measured using nine items that assess the youth's perceptions on the extent to which their parents knew issues such as the way they spend weekday and weekend nights, TV programs they watch and who their best friend is among other issues. Lastly, problem behaviour index was derived from seven items that capture issues such as carrying of weapons to school, getting into fights and carrying drugs among other issues. Cronbach's alpha was used to assess internal consistency of scores and this ranged from 0.73 for the problem behaviour index; 0.91 for the religiosity score and 0.90 for parental monitoring score. These variables were included as continuous scores in the regression models for all outcomes.

\section{Analytic approach}

Data were analyzed using Stata version 10.1 (StataCorp, 2007). Logistic regression models were used to assess the effect of migration on sexual debut among all youths who had ever had sex. For number of sexual partners during the last 12 months, we fitted a Poisson regression model. Kaplan-Meier estimates were used to examine the timing of first sex and Cox regression models used to investigate the influence of various factors on sexual debut after migration. Age at first sex is censored as some individuals may not have experienced sexual intercourse by the time of survey. Individuals are considered to be at risk from the time of in-migration or enumeration into the NUHDSS until they first become sexually active or censored at the time of the survey for those who were still virgins. Curves depicting first sexual experience by age are derived from Kaplan-Meier estimates using the complement to $I$ of the probability of not having sex at a specific age. In the Cox model, when the hazard ratio is greater than one, it means a higher risk of first sex in the corresponding category, as compared to the reference category. Conversely, the risk of first sex is lower when the hazard ratio is less than one.

\section{Results}

\section{Sample description}

Overall males make up a higher proportion of the sample $(50.4 \%)$ compared to females (49.6\%). Those aged between 15 and 19 years make up a major proportion of the sample with those below and above this age range contributing almost equal proportions. Most notable is the distribution of migrants by slum of residence with Korogocho having $81 \%$ of non-migrants as opposed to $42.6 \%$ in Viwandani while higher proportions of migrants are found in Viwandani as compared to Korogocho ( $57.4 \%$ and $18.7 \%$ respectively). Majority of the sampled youth had at least primary level of education while $54.2 \%$ come from the poorest households in the slums.

Over two thirds of the youth in the sample have lived in the slums for ten or more years while close to a fifth have lived for between 0 and 4 years. The mean duration of stay differs by sex and slum of residence with males overall staying for one year longer than females (I2.3 and II.3 years for males and females respectively). Youth in Korogocho have lived there for an average period of 14 years compared to 9.5 years for Viwandani youth (results not shown).

Table I shows the cross-tabulation results of the outcome variables by socio-demographic characteristics. Overall, non-migrants form a higher proportion of the sample. The proportion reporting to have more than one sexual partner in the year preceding the interview is higher among migrants. As far as age at sexual debut is concerned, a higher proportion of adolescents initiating sex at 14 years or below is observed among migrants as compared to non-migrants. Across all outcomes, higher proportions of females are found compared to males. Eighty one per cent of females initiated sex before the age of 15 compared to $64.9 \%$ of males. Further, $85.3 \%$ of females had more than one sexual partners compared to $64.1 \%$ among males. 
Table I: Distribution of risky sexual behaviour outcomes by selected background characteristics

\begin{tabular}{|c|c|c|c|c|c|c|}
\hline & \multicolumn{3}{|c|}{ Age at sexual debut } & \multicolumn{3}{|c|}{ Number of sexual partners } \\
\hline & $<=14$ years & $15+$ years & Total & $<=1$ & $2+$ & Total \\
\hline \multicolumn{7}{|c|}{ Migration status } \\
\hline Non-migrant & 32.3 & 67.7 & 50.6 & 29.4 & 70.6 & 51.5 \\
\hline Migrant & 20.8 & 79.2 & 49.4 & 19.8 & 80.3 & 48.5 \\
\hline \multicolumn{7}{|l|}{ Sex } \\
\hline Male & 35.1 & 64.9 & 45.9 & 35.9 & 64.1 & 47.3 \\
\hline Female & 19.4 & 80.6 & 54.1 & 14.7 & 85.3 & 52.7 \\
\hline \multicolumn{7}{|l|}{ Age } \\
\hline$<15$ & 100 & 0 & 2.9 & 71 & 29 & 3.1 \\
\hline $15-19$ & 29.2 & 70.8 & 39.5 & 28.6 & 71.4 & 39.9 \\
\hline $20-24$ & 21.3 & 78.7 & 57.6 & 19.5 & 80.5 & 57 \\
\hline \multicolumn{7}{|c|}{ Slum of residence } \\
\hline Korogocho & 30.3 & 69.8 & 51.9 & 27.9 & 72.2 & 51.5 \\
\hline Viwandani & 22.7 & 77.3 & 48.2 & 21.4 & 78.6 & 48.5 \\
\hline \multicolumn{7}{|l|}{ Ethnic group } \\
\hline Kikuyu & 29.3 & 70.7 & 35.8 & 29.2 & 70.8 & 36.4 \\
\hline Luhya & 27.8 & 72.2 & 16.4 & 22.7 & 77.3 & 16 \\
\hline Luo & 24.8 & 75.2 & 19.7 & 23.7 & 76.3 & 19.7 \\
\hline Kamba & 23.9 & 76.1 & 16.8 & 20.6 & 79.4 & 16.2 \\
\hline Other & 20.1 & 79.9 & 11.4 & 17.9 & 82.1 & 11.7 \\
\hline \multicolumn{7}{|c|}{ Household SES } \\
\hline Least Poor & 25 & 75 & 43.3 & 24.1 & 75.9 & 43.7 \\
\hline Poorest & 27.3 & 72.7 & 56.7 & 25.2 & 74.9 & 56.3 \\
\hline \multicolumn{7}{|l|}{ Education } \\
\hline No education & 31.3 & 68.7 & 2.1 & 14.9 & 85.1 & 2.1 \\
\hline Primary & 28.1 & 71.9 & 77.3 & 26.7 & 73.3 & 77.8 \\
\hline Secondary+ & 17.3 & 82.7 & 20.6 & 18 & 82 & 20.1 \\
\hline \multicolumn{7}{|l|}{ Religion } \\
\hline Catholic & 24.9 & 75.2 & 29 & 22.3 & 77.7 & 28.7 \\
\hline Protestant & 24.5 & 75.5 & 30 & 24.9 & 75.1 & 31 \\
\hline Pentecostal & 25.3 & 74.7 & 20.3 & 25.6 & 74.4 & 19.6 \\
\hline Islam & 18.4 & 81.6 & 8.1 & 18.9 & 81.1 & 7.5 \\
\hline No religion & 43.3 & 56.7 & 12.5 & 31.6 & 68.4 & 13.2 \\
\hline
\end{tabular}




\begin{tabular}{l|rrr|rrr|} 
Duration of stay in slum & & & & & \\
0-4 years & 17.8 & 82.2 & 30.7 & 16.9 & 83.1 & 30 \\
$5-9$ years & 32.2 & 67.8 & 10.9 & 18.1 & 81.9 & 10.9 \\
$10+$ years & 30.2 & 69.8 & 58.4 & 29.9 & 70.1 & 59.1 \\
\hline Total & 26.6 & 73.4 & 100 & 24.7 & 75.3 & 100 \\
N & 242 & 660 & & 238 & 725 & \\
\hline
\end{tabular}

\section{Determinants of risky sexual behaviour among youth in slums}

We assessed the factors predicting risky sexual behaviour while controlling for the migration status of young people. Univariate models were fitted for each outcome then covariates added to the model one at a time. The main explanatory variable was significant in the univariate models only for sexual debut. However, it loses statistical significance when age is introduced into the model. For the model on number of sexual partners, the migration status only becomes significant after introducing the parental monitoring score into the model, meaning that differences in monitoring for migrants and nonmigrants play a role in sexual partnerships. We present in Table 2 a summary of factors that predict risky sexual behaviour among migrant youth.

The factors predicting early sexual debut were, sex, age, religiosity, slum of residence, and education. Mother's presence was marginally significant. Youth with higher religiosity score i.e. those who tended to be very religious were less likely to initiate sex early compared to less religious youth. Those with a secondary school education or higher were $49 \%$ less likely to initiate sex early compared to those with primary level of education.
Females were $52 \%$ less likely to initiate sex early compared to males while a year's increase in age was associated with reduced likelihood of early sexual initiation as was residence in Viwandani.

Having multiple sexual partners in the one year preceding the interview is predicted by the migration status of the youth, age, problem behaviour score, religion, religiosity, ethnicity and educational attainment. Every unit increase in problem behaviour index is significantly associated with a 1.2 increase in the likelihood of having multiple sexual partners over the last 12 months. For migrant youth in the two slums, the likelihood of having multiple sexual partners is reduced by $27 \%$ compared to that of those who were born in the slums. Every year increase in age was significantly associated with a $13 \%$ increase in the likelihood of having multiple sexual partners while a unit increase in the religiosity score was associated with a 3 fold increase in the likelihood of having multiple sexual partners during the reference period. Religion appears protective over multiple partnering except among youths of Islamic faith which is expected considering Islam's stance on polygamy.

A separate model controlling for the place where the migrant youth were socialized (results not shown) shows similar direction of effect on the outcomes.

Table 2: Regression results for risky sexual behaviour among youth

\begin{tabular}{|c|c|c|c|c|}
\hline \multirow{2}{*}{ Variables } & \multicolumn{2}{|c|}{ Sexual Debut } & \multicolumn{2}{|c|}{ Number of sexual partners $^{\beta}$} \\
\hline & OR & $95 \% \mathrm{Cl}$ & IRR & $95 \% \mathrm{Cl}$ \\
\hline \multicolumn{5}{|c|}{ Migration status (Ref:non-migrant) } \\
\hline Migrant & 0.77 & $0.38-1.55$ & $0.73^{* *}$ & $0.57-0.93$ \\
\hline \multicolumn{5}{|l|}{ Sex: Ref = Male } \\
\hline Female & $0.48 * * *$ & $0.30-0.75$ & 0.99 & $0.80-1.22$ \\
\hline Age & $0.62 * * *$ & $0.55-0.7$ I & I.13*** & $1.06-1.20$ \\
\hline Age at first sex & - & & 0.98 & $0.94-1.02$ \\
\hline
\end{tabular}




\begin{tabular}{|c|c|c|c|c|}
\hline \multirow{2}{*}{ Variables } & \multicolumn{2}{|c|}{ Sexual Debut } & \multicolumn{2}{|c|}{ Number of sexual partners ${ }^{B}$} \\
\hline & OR & $95 \% \mathrm{Cl}$ & IRR & $95 \% \mathrm{Cl}$ \\
\hline $\begin{array}{l}\text { Religiosity score } \\
\text { Father's presence: Ref= }\end{array}$ & $\mathrm{I} .89 * * *$ & $1.28-2.80$ & $2.94^{* *}$ & $1.25-6.9 \mid$ \\
\hline \multicolumn{5}{|c|}{ Mother's presence: Ref $=$ Yes } \\
\hline No & $4.18^{*}$ & $0.90-19.38$ & 1.09 & $0.62-1.91$ \\
\hline \multicolumn{5}{|c|}{ Slum of residence: Ref=Korogocho } \\
\hline $\begin{array}{l}\text { Viwandani } \\
\text { In Income generation: } \mathbf{R}\end{array}$ & $0.44^{* * * *}$ & $0.25-0.78$ & 1.20 & $0.93-1.56$ \\
\hline No & 0.58 & $0.26-1.28$ & 1.12 & $0.79-1.59$ \\
\hline Parental monitoring score & 1.25 & $0.91-1.73$ & 0.96 & $0.83-1.10$ \\
\hline Problem behaviour score & 1.18 & $0.90-1.54$ & 1.21 & I.09-I.34 \\
\hline \multicolumn{5}{|c|}{ Household wealth: Ref=Least poor } \\
\hline Poorest & 1.29 & $0.82-2.02$ & 0.93 & $0.76-1.13$ \\
\hline \multicolumn{5}{|l|}{ Ethnic group: Ref=Kikuyu } \\
\hline Luhya & 0.91 & $0.49-1.68$ & $1.45^{* *}$ & $1.09-1.94$ \\
\hline Luo & 0.83 & $0.48-1.45$ & 1.16 & $0.89-1.52$ \\
\hline Kamba & 1.4 & $0.58-3.39$ & 1.17 & $0.82-1.68$ \\
\hline Other & 2.07 & $0.72-5.95$ & 1.08 & $0.7 I-I .64$ \\
\hline \multicolumn{5}{|c|}{ Education level: Ref $=$ Primary } \\
\hline No education & 0.58 & $0.15-2.26$ & 1.23 & $0.60-2.52$ \\
\hline Secondary+ & $0.5 I^{* *}$ & $0.27-0.98$ & $1.28 *$ & $0.99-1.66$ \\
\hline \multicolumn{5}{|l|}{ Ever married: Ref $=$ Yes } \\
\hline No & 0.58 & $0.24-I .4 I$ & & \\
\hline $\mathrm{N}$ & 467 & & 468 & \\
\hline R-square & 0.2293 & & 0.056 & \\
\hline Chi & $105.47^{* * *}$ & & 63.6 & \\
\hline
\end{tabular}

Note: Significance levels- ${ }^{* * *}=1 \%{ }^{* *}=5 \%$ and ${ }^{*}=10 \% ;{ }^{\beta}$ : Poisson model was used .

Predictors of timing of first sexual intercourse among migrant youth

The Kaplan Meier function was used to assess the probability to initiate sexual intercourse over the observation period. Results show that immediately after in-migration, both sexes tend to take the same time to make the transition into their first sex (Figure I). However, after the first year more males have a higher probability to make the transition to first sex than females. This continues up to the sixth year when the probability to initiate sex levels off for both sexes. 


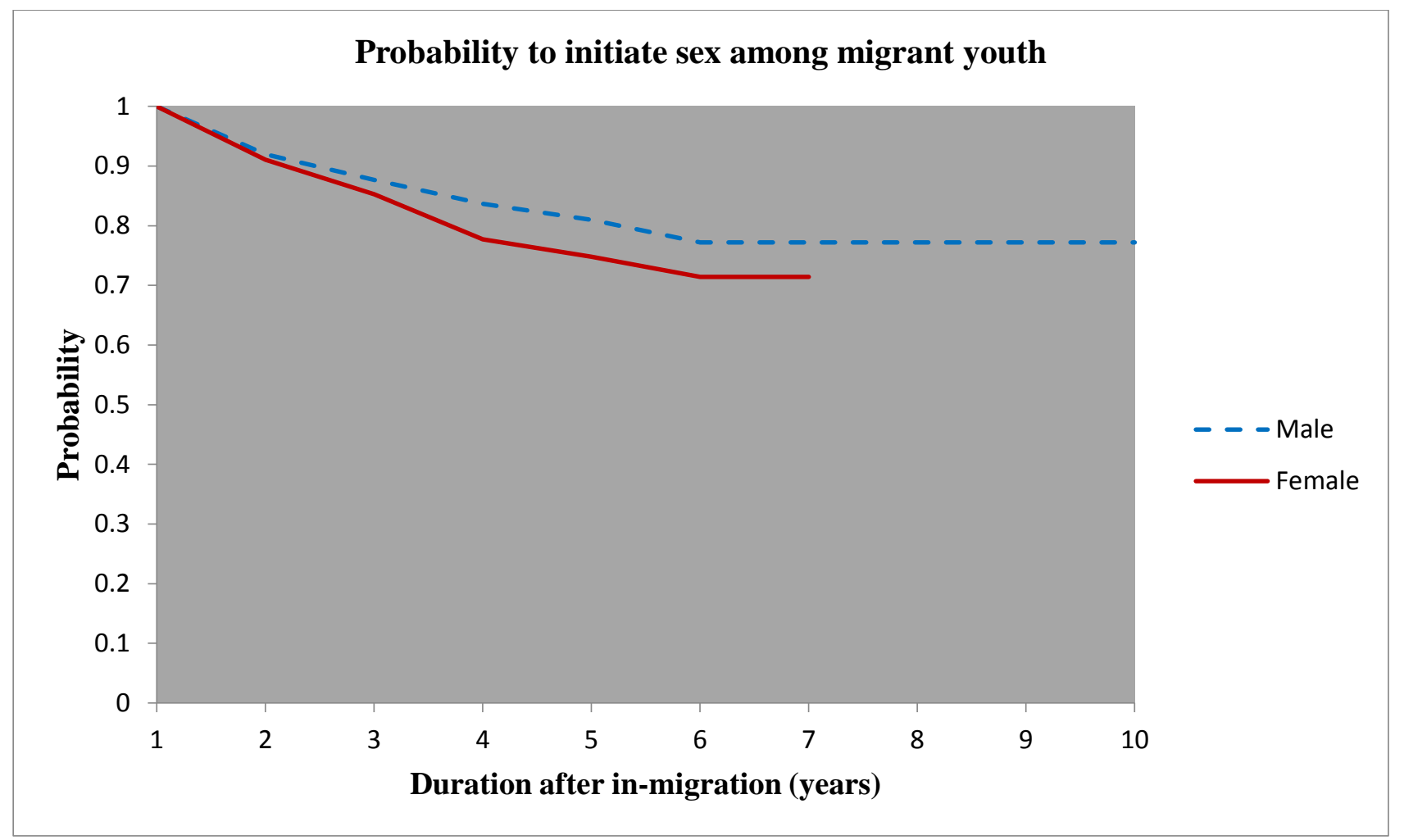

Figure 1: Probability to initiate sex over time by gender

For the multivariate analysis, we use the Cox proportional hazards model to assess the factors associated with timing of first sexual intercourse upon in-migration into the slums. Table 3 shows the hazard ratios corresponding to factors associated with time to first sex among migrant adolescents. The results show that the age at in-migration to the slums, slum of residence, sex of migrant and problem behaviour significantly matter when it comes to timing of first sex for migrant adolescents while parental monitoring is marginally significant.
An increase in a single year of the age at in-migration is associated with a $39 \%$ increase in the risk of initiating sex soon after migration.

Problem behaviour was significantly associated with the timing of sexual initiation after in-migration. Indeed, a unit increase in the problem behaviour score was associated with a doubling in the risk for initiating sex upon in-migration. Youth migrating into Korogocho appear to be less likely to initiate sex soon after in-migration compared to those moving into Viwandani. 
Table 3: Hazard ratios for time to first sex among migrant adolescents

\begin{tabular}{|c|c|c|}
\hline Variables & Hazard Ratio & $95 \% \mathrm{Cl}$ \\
\hline Female (Ref $=$ Male) & $1.95^{* * * *}$ & $1.32-2.89$ \\
\hline Age at migration & $1.39 * * *$ & $1.29-1.49$ \\
\hline \multicolumn{3}{|l|}{ Slum of residence: Ref $=$ Viwandani } \\
\hline Korogocho & $0.59 * *$ & $0.38-0.91$ \\
\hline No Father in life (Ref $=$ Yes) & 0.85 & $0.55-1.32$ \\
\hline No Mother in life (Ref $=$ Yes) & 1.22 & $0.60-2.46$ \\
\hline Parental monitoring & $0.80 *$ & $0.62-1.02$ \\
\hline Problem behaviour score & $2.00 * * *$ & $1.54-2.58$ \\
\hline Other religion $($ Ref $=$ Christian) & 0.99 & $0.56-1.75$ \\
\hline Religiosity score & 1.20 & $0.95-1.53$ \\
\hline \multicolumn{3}{|l|}{ Ethnic: Ref= Kikuyu } \\
\hline Luhya & 1.18 & $0.62-2.25$ \\
\hline Luo & 1.15 & $0.66-2.00$ \\
\hline Kamba & 1.09 & $0.6 I-1.94$ \\
\hline Other & 1.35 & $0.67-2.71$ \\
\hline \multicolumn{3}{|c|}{ Household wealth: Ref $=$ Least poor } \\
\hline Poorest & 1.12 & $0.74-I .70$ \\
\hline Time at risk (person-years) & 2170.51 & \\
\hline $\mathbf{N}$ & 629 & \\
\hline Number of failures & $|2|$ & \\
\hline
\end{tabular}

Note: Significance- ${ }^{* * *}=1 \% ;{ }^{* *}=5 \%$ and ${ }^{*}=10 \%$

A separate model for all youth, controlling for the migration status of the youth was fitted (results not shown) and the results show that migration is not a significant factor in the risk of engaging in sexual intercourse, although the hazard ratio indicates an increased risk.

\section{Limitations}

The study had the following limitations:

Data on religiosity was not collected prospectively and this prevented the assessment of its effect on the outcomes as we could not ascertain the time sequence of events i.e. whether young people became more religious before or after the outcomes studied.

Inclusion of older youth and married youth in the study obviated some of the outcomes such as sexual debut and this could have led to some bias in the findings.

Despite these limitations we are confident that the data presented unique strengths in studying the role of migration in risky sexual behaviour.

\section{Discussion and Conclusion}

The finding that there is a difference in age at sexual debut between males and females points to a possible role of societal/cultural acceptance of boys' premarital sexual activity even while frowning on the same for females (Awusabo-Asare et al., 2004).

Multiple partners in the year preceding the survey was significantly predicted by problem behaviour this is in line with findings that show that youth with problem behaviour were more likely to engage in risky behaviour including risky sexual behaviour among these being multiple sexual partners (Hango, 
2006). Social context is also important in multiple partnerships as shown by the finding that migrant youth were less likely to have multiple partners compared to those born in the slums; supporting the finding by Zulu and colleagues (Zulu et al., 2002). That religiosity is negatively associated with multiple partners is worrying since it is counter what is expected of highly religious individuals. While the measure of religiosity in this study does not give an indication when the youth became highly religious with respect to having multiple partners, it is worth noting the possible risk faced by highly religious youth. A study among Nigerian youth has shown that 'born again' youth were less likely to use condoms if the relationship was viewed as 'moral (where the partner is 'born again') (Smith, 2004). It is possible that such views extend to the number of partners among the highly religious youth.

Older age at in-migration as an important predictor of timing of sexual initiation among migrants could be linked to the sense of freedom older migrant youth might enjoy upon in-migration especially if they are not living with their parents/guardians. This might lead them to engage in sexual relations as there is no monitoring from parents. Also significant was problem behaviour which has been shown to develop among children who change residence frequently (Hango, 2006) mainly as a way of coping with the loss of familiar environment, friends and other social capital (Coleman, 1988). Problem behaviour can lead adolescents into engaging in sexual activity soon after in-migration to compensate for the loss and as a way of forming new bonds or fitting into the new environment.

The difference in timing of sexual initiation among migrants by slum of residence might reflect the differences in household structure in the two slums. For instance, Korogocho is characterised by families living together while Viwandani has fewer families living together and more single migrants living on their own. Thus it is possible that parental monitoring is acting to reduce the risk among those migrating to Korogocho since parents/guardians are present while among migrants in Viwandani, parental controls are weakened due to their absence and distance which make monitoring almost impossible. Parental presence has been shown to have positive effects on youth's sexual behaviour (Ngom et al., 2003).

This study demonstrates the risk and protective factors for risky sexual behaviour among youth. We note the importance of problem behaviour, and religiosity in the sexual behaviour of youth. However, there is need to assess the role of religion and religiosity in increasing the risk of risky sexual behaviour among these youths. The study does not find migrant youth to be at higher risk of engaging in risky sexual behaviour.

The fact that youth with problem behaviour, face increased risk of initiating sex soon after in-migration points to the need for [sending] families to have in place strong monitoring mechanisms at the destination to watch over migrant youth since monitoring reduces the risk of initiating sex soon after migration.

\section{Acknowledgements}

We are grateful to the Wellcome Trust (Grant No. GR 07830 M) for funding the data collection, analysis and writing time. Publication was made possible through support from the Bill and Melinda Gates Foundation (Grant No. OPP 1021893). This research was also made possible through the generous core funding to APHRC by the William and Flora Hewlett Foundation; and the Swedish International Development Cooperation (SIDA).

\section{Author Contributions}

KM conceptualized the paper idea and wrote the first draft. NM and BM carried out the literature review, DB conducted data analysis. All authors contributed to writing the discussion. The final draft was reviewed and signed off by all authors.

\section{References}

Adedimeji, A. A. 2005. Beyond knowledge and behavior change: The social-structural context of HIV/AIDS risk perceptions and protective behavior among young urban slum inhabitants in Nigeria. Boston: Department of Population and International Health, Harvard School of Public Health.

African Population and Health Research Center 2002. Population and Health Dynamics in Nairobi's Informal Settlements: Report of the Nairobi Cross-sectional Slums Survey (NCSS) 2000, Nairobi, African Population and Health Research Center.

African Population and Health Research Center 2009. Nairobi Urban Health \& Demographic Surveillance System: Summary Indicators.

Awusabo-Asare, K., Abane, A. M. \& Kumi-Kyereme, A. 2004. Adolescent Sexual and Reproductive Health in Ghana: A Synthesis of Research 
Evidence. New York: The Alan Guttmacher Institute.

Blanc, A. K. \& Way, A. A. 1998. Sexual Behavior and Contraceptive Knowledge and Use among Adolescents in Developing Countries. Studies in Family Planning, 29, 106-II6.

Blum, R. W. 2002. Mother's influence on Teen Sex: Connections that promote postponing sexual intercourse. Minneapolis: Center for Adolescent Health and Development, University of Minnesota.

Brockerhoff, M. \& Biddlecom, A. 1999. Migration, sexual behavior and the risk of HIV in Kenya. International Migration Review, 33, 833-856.

Central Bureau of Statistics 2000. Welfare Monitoring Survey III: Government Priorities Nairobi: Ministry of Planning and National Development.

Coleman, J. S. 1988. Social Capital in the Creation of Human Capital. . The American Journal of Sociology. Organizations and Institutions: Sociological and Economic Approaches to the Analysis of Social Structure 94 Supplement, S95SI 20.

French, D. C. \& Dishion, T. J. 2003. Predictors of Early Initiation of sexual Intercourse among HighRisk adolescents. The Journal of Early Adolescence, 23, 295-315.

Gage, A. J. 1998. Sexual activity and contraceptive use: The components of the decisionmaking process. Studies in Family Planning, 29, I54- 166.

Gurmu, E., Goldstein, S. \& Goldstein, A. 2000. Migration, Gender and Health Survey in Five Regions of Ethiopia:1998. A United Nation Training and Research Project on the Interrelations of Migration and Economic Change, Women's Status, Reproduction and Health. Addis Ababa: Addis Ababa University and Providence: Brown University.

Hango, D. W. 2006. The long-term Effect of Childhood Residential Mobility on Educational Attainment The sociological Quarterly 47, 631664.

Isiugo-Abanihe, U. C. \& Oyediran, K. A. 2004. Household socioeconomic status and sexual behaviour among Nigerian female youth. African Population Studies, 19, 8I-98.

Kessides, C. 2006. The Urban Transition in SubSaharan Africa. Washington, DC: Cities Alliance and World Bank.

Lurie, M., Williams, B., Zuma, K., Mkaya-Mwamburi, D., Garnett, G., Sturm, A., Sweat, M., Gittelsohn,
J. \& Karim, S. A. 2003. The impact of migration on HIV-I transmission in South Africa: a study of migrant and nonmigrant men and their partners. Sexually transmitted diseases, 30, I49-156.

Mabogunje, A. L. 2007. Global urban poverty research: The African case. Urban Update. Washington, DC: Woodrow Wilson International Center for Scholars.

Matrix Development Consultants 1993. Nairobi's Informal Settlements: An inventory. A Report Prepared for USAID/REDSO/ESA, Nairobi, USAID.

Mberu, B. U. 2005. Who Moves and Who Stays? Rural Out-Migration in Nigeria. Journal of Population Research, 22 I4I-I6I.

Mugisha, F., Arinaitwe-Mugisha, J. \& Hagembe, B. O. N. 2003. Alcohol, substance and drug use among urban slum adolescents in Nairobi, Kenya. Cities, 20, 23I-240.

Mugisha, F. \& Zulu, E. M. 2004. The Influence of Alcohol, Drugs and Substance Abuse on Sexual Relationships and Perception of Risk to HIV Infection Among Adolescents in the Informal Settlements of Nairobi. Journal of Youth Studies, 7, 279-293.

National Research Council and Institute of Medicine 2005. Growing Up Global: The Changing Transitions To Adulthood In Developing Countries, Washington, DC, The National Academies Press.

Ngom, P., Magadi, M. A. \& Owuor, T. 2003. Parental presence and adolescent reproductive health among the Nairobi urban poor. Journal of Adolescent Health, 33, 369-377.

Niser 1997. Nigeria Migration and Urbanization Survey. Ibadan: Nigeria Institute for Social and Economic Research.

Oxfam. 2009. Urban Poverty and Vulnerability in Kenya: Background analysis for the preparation of an Oxfam GB Urban Programme focused on Nairobi [Online]. Available: www.irinnews.org [Accessed November, 3 2010].

Quinn, T. C. 1994. Population Migration and the Spread of Types $\mathrm{I}$ and 2 Human Immunodeficiency Viruses. Proceedings of the National Academy of Sciences, 91, 2407-24I4.

Smith, D. J. 2000. "These Girls Today Na WarO":Premarital Sexuality and Modern Identity in Southeastern Nigeria. Africa Today, 47, 99-1 20.

Smith, D. J. 2004. Youth, Sin and Sex in Nigeria: Christianity and HIV/AIDS-Related Beliefs and 
Behaviour among Rural-Urban Migrants. Culture, Health \& Sexuality, 6, 425-437.

Statacorp 2007. Stata Statistical Software: Release 10.I College Station, TX: StataCorp LP.

Taffa, N. 2003. A comparison of pregnancy and child health outcomes between teenage and adult mothers in the slums of Nairobi, Kenya. International Journal of Adolescent Medicine and Health, 15, 321-9.

Townsend, N. 1997. Men, migration, and households in Botswana: an exploration of connections over time and space. Journal of Southern African Studies, 23, 405-420.

Un-Habitat 2003. The Challenge of Slums: Global Report on Human Settlements

United-Nations 1994. AIDS and the Demography of Africa. New York United Nations.

White, M. J., Mberu, B. U. \& Collinson, M. A. 2008. African urbanization: Recent trends and implications. In: Martine, G., McGranahan, G., Montgomery, M. \& Fernandez-Castilla , R. (eds.) The New Urban Frontier. London: Earthscan.

Zulu, E., Beguy, D., Mudege, N., Muindi, K. \& Batten, L. 2009. Characteristics of recent inmigrants in the Nairobi Urban Health Demographic Surveillance System. Population Association of America Annual Meeting [Session 170: The structuring of Internal Migration]. Detroit, Michigan.

Zulu, E., Konseiga, A., Muindi, K., Darteh, E. \& Mberu, B. 2006. Migration and the Urbanization of Poverty in sub-Saharan Africa: The Case of Nairobi City, Kenya. 2006 PAA Annual Meeting. Los Angeles.

Zulu, E. M., Dodoo, F. N.-A. \& Ezeh, A. C. 2002. Sexual risk-taking in the slums of Nairobi, Kenya, 1993-98. Population Studies, 56, 3 I I-323. 